\title{
Use of colonic pouches in treatment of mid and low rectal cancer: Better patient selection results in better functional outcome
}

\author{
Deya M M Marzouk, MD FRCS(Ed) \\ Department of General Surgery, Ain-Shams University, Cairo, Egypt.
}

\begin{abstract}
Background: Addition of a colonic pouch to an ultralow anterior resection or a coloanal anastomosis can improve the functional outcome, but may also cause evacuation difficulties. This study was conducted to evaluate the selective use of colonic pouches, based upon the diameter of the proximal colon.

Methods: Twenty-nine rectal cancer patients underwent ultralow anterior resection or coloanal anastomosis, between July 1998 and January 2000. Seventeen had a stapled straight anastomosis, while 12 had a stapled colonic pouch-anal anastomosis. The method of reconstruction was selected intraoperatively based on the diameter of the proximal colon as measured by metal sizers. The colonic J-pouch was constructed with 6-cm limbs using GIA60. Median follow-up was 9 months (range 6- 23 months). Data about complications, tumour characteristics and height of anastomoses were collected. Postoperative bowel function was assessed at 3 and 6 months after surgery or closure of ileostomy using a standard bowel function questionnaire.

Results: The 2 groups were comparable regarding age, sex, Dukes stage, resection margins and height of the anastomosis. All anastomoses were $2-5.5 \mathrm{~cm}$ from the anal verge. The operations were covered by a loop ileostomy in 2 of the straight anastomoses and 4 of the pouches. Two patients had intraoperative complications; splenic injury needing splenectomy and bleeding from pelvic side walls requiring packing. One patient died from multiorgan failure on the 6th postoperative day and was excluded from functional analysis. Four patients had postoperative complications including 2 adhesive bowel obstructions, major wound infection and a subphrenic collection. There were no clinical leaks or pouch-vaginal fistulae. Colonic pouches proved to result in superior functional result in the first 6 months postoperatively compared with straight anastomoses. Pouch patients had less frequency, urgency and need for constipating drugs. None of the pouch patients had evacuation difficulties. Adaptation of straight anastomosis patients resulted in comparable bowel function after 6 months in most patients.

Conclusions: Patients with narrow proximal colon, not accepting $31 \mathrm{~mm}$ sizer need a colonic pouch added to ultralow or coloanal anstomosis to achieve good postoperative bowel function. Other patients with capacious proximal colon can be expected to achieve equally good functional results after 6 months without the need for a colonic pouch.
\end{abstract}

\section{Introduction:}

Controversy still lingers on regarding the role of colonic pouches after rectal resections. Many proponents suggest they should be used routinely after low resections. However the vast majority of colorectal surgeons are still concerned about their potential for evacuation problems and don't use them at all. This study was conducted to evaluate whether it is possible to selectively use colonic pouches, after ultralow rectal resections based upon the diameter of the proximal colon with acceptable function in all patients.

\section{Patients and methods:}

\section{Patients:}

Forty-six patients with rectal cancer palpable on digital rectal examination (mid and low rectal cancer), were seen at Queen Elizabeth hospital, Margate, Kent between July 1998 and January 2000. Twenty-nine patients (17 men and 12 women) had restorative resections (ultralow anterior resections and coloanal anastomoses) and are the subject of the present study. They included 17 patients who had a stapled straight anastomosis (group I) and 12 
who had a stapled colonic pouch-anal anastomosis (group II). One patient in group I died from cardiorespiratory complications on the 6th postoperative day and was excluded from analysis of postoperative function. All patients were treated by one surgeon (DM).

Twelve patients had non-restorative resections (10 abdomenoperineal resections and 2 hartmann's procedure). Five more patients did not have surgery, including 2 who were found unfit for major surgery, 1 patient refused surgery and 2 patients presented with disseminated pulmonary $\&$ hepatic metastases. The latter 5 patients had radiotharapy with or without rectal stent placement. Seven other patients had cancers in the upper third of the rectum or the rectosigmoid junction seen during the same period were all treated by standard low anterior resection without addition of colonic pouches and were not included in the study.

Selection of the method of reconstruction was done intraoperatively based on the diameter of the proximal colon as measured by metal sizers. All patients with proximal colon accepting $31 \mathrm{~mm}$ sizer were selected for a straight coloanal anastomosis (except in 3 patients with inadequate colonic length to perform a pouch).

\section{Surgical technique:}

Patients were fully informed and consented regarding the extent of the operation, the possible need for removal of adjacent organs, possible need for a defunctioning stoma or even an end colostomy if an abdominoperineal excision becomes necessary. Male patients were warned about the small risk of impotence following surgery.

All patients had mechanical bowel preparation using Kleen-prepÆ.

General endotracheal anaesthesia, usually with epidural analgesia was administered Peroperative parenteral antibiotic prophylaxis was administered using cefuroxime and metronidazole and continued for 3 days postoperatively. The patient was then placed in Lloyd-Davies position on the operating table.

The skin of the whole abdomen, the genitalia and the perineum was prepared from the nipples to upper third of the thighs. No purse string suture was applied until a decision has been made that a sphincter saving resection was not possible. A long midline incision was usually used for access.

A full exploratory laparotomy was the initial step to look for spread missed on preoperative scanning. This included assessment of the liver, the omentum, the visceral and parietal peritoneum, and the lymph nodes on the posterior abdominal wall as well as the rest of the colon. The tumour itself was assessed last and plans made for any additional en-bloc organ resection.

The field of operation was next displayed by packing the small intestine underneath the liver in the right hypochondrium, using 2 large abdominal packs and by applying a self retaining retractor to the edges of the incision to spread it.

Full mobilization of the sigmoid colon and in most cases the splenic flexure and distal half of the transverse colon was done next. This was a crucial step before division of bowel in order to assess the length of colon needed to achieve an anastomosis without compromising a radical cancer resection with lymph node clearance. Both ureters were identified and secured during mobilization of the colon.

Following full mobilization, the colon was pulled downwards to see where it will reach the symphysis pubis and the level of bowel division was chosen at such point. The bowel was then divided between a Parker-Kerr crushing clamp (distally) and an umblical cord clamp (proximally).

The inferior mesenteric vessels were ligated and divided next along with vessels in the sigmoid mesentery. A high tie was not used if the retroperitoneum felt clinically negative and if it meant compromising blood supply and consequently intestinal length. If palpation of the retroperitoneum revealed possible enlarged lymph nodes then a high tie was employed.

Once bowel was divided, the colon was pulled towards the symphysis pubis and the presacral nerves identified and preserved. Rectal mobilization was started by entering the retrorectal space posteriorly, using a combination of sharp and blunt dissection and staying behind all of the mesorectum to the tip of the coccyx. Next the rectum was partially mobilized anteriorly by separating it from the 
fascia of Denonvillers (occasionally dividing it and staying behind the seminal vesicles in bulky anterior tumours and also in patients who had preoperative radiotherapy). With posterior and anterior mobilization done, the lateral ligaments were defined and divided as far laterally as possible after checking the ureters and the iliac vessels location. This was usually done using diathermy and scissors (without clamping) to achieve the widest possible circumferential clearance. Further mobilization all around was continued until dissection reached the anorectal ring.

After full rectal mobilization and provided there was a clearance of at least $2 \mathrm{~cm}$ of unstretched rectum below the tumour a right angled rectal clamp was applied $1 \mathrm{~cm}$ or more below the palpable tumour edge. A transverse stapling instrument (Autosuture Roticulator 55 or preferably Ethicon Proximate axis) was next applied more distally, pushed downwards as far as it will go and fired.

A long knife was then used to divide the specimen flush with the stapler and remove it. The specimen was then opened to check on the unstretched distal margin and if this was not deemed sufficient, further resection of the anorectal remmnant was attempted or the operation was converted into a manual coloanal anastomosis or an abdomenoperineal depending on circumstances.

The pelvis was then inspected to ensure that a total mesorectal excision has been carried out (revealed by the glistening presacral fascia lying bare without any fat and only the median sacral vessels. Haemostasis of the pelvis was then carried out

The proximal bowel was next milked backwards and a non-crushing intestinal clamp was next applied to the proximal bowel 10-15 $\mathrm{cm}$ from the transected bowel end. The crushed bowel end (umbilical cord clamp) was next excised with knife and cleaned thoroughly with several wet small gauze swabs. The proximal colon was next sized using metal sizers $(25,28$ and $31 \mathrm{~mm})$. If the proximal bowel admitted sizer 31 , then a straight anastomosis was performed using a Premium CEEA 31 stapler gun. If proximal colon was found to be smaller than size 31 then a J-shaped colonic pouch was constructed with 6-cm limbs using a linear GIA60 stapler. If a straight anastomosis was chosen then a 3/0 prolene suture was used to create a proximal purse string (Whip stitch) and the proximal colonic end was tied after introduction of the $31 \mathrm{~mm}$ anvil. If a colonic pouch was selected, it was created by folding $12-14 \mathrm{~cm}$ segment of the transected proximal colon onto itself. An enterotomy was made at the apex of the $\mathrm{J}$ and a GIA 60 linear stapler introduced through it and fired to create the pouch. The open upturned end of the short limb of the pouch was then closed in 2 layers with vicryl $2 / 0$ sutures.

The rectal stump was finally washed with $1 \%$ chlorhexidine solution and a standard double stapled anastomosis performed. The pelvis was then filled with sterile water and the anastomosis was tested by air insufflation through a sigmoidoscope passed through the anus to check for leakage. The doughnuts were also checked for completeness. If there was any doubt about anastomotic integrity then a loop ileostomy was raised. Finally the pelvis is irrigated with several litres of warm sterile water and 2 large suction drains were left and the incision closed.

\section{Postoperative evaluation and follow-up:}

Record of all intraoperative, postoperative complications, tumour stage, distal and circumferential margins were collected. Postoperative bowel function was assessed at 3,6 and 12 months after surgery or closure of the loop ileostomy using a detailed bowel function questionnaire (Marzouk, 1990).

\section{Statistical methods:}

Collected data are expressed as median (range) and analysed using the computer statistical package Statistica version 5 and Arcus professional statistics version version 2.03s. McNemar Chi-square test and MannWhitney U test were used to assess statistical differences between the 2 groups, where appropriate. $\mathrm{P}$ value $<0.05$ was considered significant.

\section{Results:}

There were no significant differences between the 2 groups regarding age, sex, and tumour height above anal verge or use of preoperative radiation therapy. Likewise Dukes 
stage, surgical margins and anastomotic height from the anal verge were similar (table $1 \& 2$ )

There was one mortality $(3.4 \%)$ in a male patient who underwent en bloc resection of an extensive tumour filling most of the rectum with partial cystectomy and small bowel resection. He required packing of the pelvis during his initial operation, packs could not be removed after 48 hours because of continued ooze and was removed at 72 hours. He had

Table 1: Patients' characteristics and complications of surgery

\begin{tabular}{|c|c|c|c|}
\hline & $\begin{array}{l}\text { Group I } \\
(\mathbf{n}=17) \\
\text { Straight }\end{array}$ & $\begin{array}{l}\text { Group II } \\
(\mathrm{n}=12) \\
\text { J pouch }\end{array}$ & $P$ value \\
\hline Median age (range) & $68(48-90)$ & $62(47-81)$ & N.S. \\
\hline Sex & $10 \mathrm{M}, 7 \mathrm{~F}$ & $7 \mathrm{M}, 5 \mathrm{~F}$ & \\
\hline $\begin{array}{l}\text { Intraoperative } \\
\text { complications }\end{array}$ & $\begin{array}{l}2 / 17 \\
1 \text { splenic injury } \\
\text { resulting in } \\
\text { splenectomy } \\
1 \text { bleeding from } \\
\text { pelvis requiring } \\
\text { packing }\end{array}$ & $0 / 12$ & N.S. \\
\hline Stoma formation & $2 / 17$ & $4 / 12$ & N.S. \\
\hline $\begin{array}{l}\text { Length of hospital stay } \\
\text { (days) }\end{array}$ & $10(8-14)$ & $10(8-12)$ & N.S. \\
\hline Mortality & $1 / 17$ & $0 / 12$ & N.S. \\
\hline Clinical leakage & $0 / 16$ & $0 / 12$ & N.S. \\
\hline $\begin{array}{l}\text { Level of anastomosis from } \\
\text { anal verge } \\
\text { Median (range) } \mathrm{cm}\end{array}$ & $3(2-5.5)$ & $2.5(2-4)$ & N.S. \\
\hline Anastomotic stenosis & $1 / 16$ & $0 / 12$ & N.S. \\
\hline $\begin{array}{l}\text { Postoperative } \\
\text { complications }\end{array}$ & $\begin{array}{l}2 / 17 \\
1 \text { subphrenic } \\
\text { collection } \\
1 \text { adhesive intestinal } \\
\text { obstruction }\end{array}$ & $\begin{array}{l}2 / 12 \\
1 \text { major wound } \\
\text { infection } \\
1 \text { adhesive intestinal } \\
\text { obstruction }\end{array}$ & \\
\hline
\end{tabular}

uncontrollable postoperative sepsis and died from multiorgan failure. The only significant morbidity in this series was a patient whose spleen was injured and had to be removed and subsequently developed a subphrenic collection which needed percutaneous drainage. Two more patients had adhesive obstruction, which resolved on conservative management.

Stomas were only used in $21 \%$ of patients $(6 / 29)$. This included 2 patients with straight anastomoses and 4 patients with pouches. Five stomas were done because of air leakage on testing or incomplete doughnuts and one because of concern about blood supply to the pouch. None of the patients developed clinical leakage, pelvic sepsis or rectovaginal fistulae.

* Statistically significant, McNemar ChiSquared test

The median follow-up was 9 (range 6-23) months. All patients had a minimum follow- 


\begin{tabular}{|c|c|c|c|}
\hline & $\begin{array}{l}\text { Group I } \\
(\mathbf{n}=\mathbf{1 7}) \\
\text { Straight }\end{array}$ & $\begin{array}{l}\text { Group II } \\
(\mathrm{n}=12) \\
\text { J pouch }\end{array}$ & P value \\
\hline $\begin{array}{l}\text { Distance of lower border } \\
\text { of tumour from anal verge } \\
\text { Median (range) } \\
5 \mathrm{~cm} \\
6 \mathrm{~cm} \\
7 \mathrm{~cm} \\
8 \mathrm{~cm} \\
9-10 \mathrm{~cm}\end{array}$ & $\begin{array}{l}7(5-10) \mathrm{cm} \\
3 \text { patients } \\
4 \text { patients } \\
4 \text { patients } \\
3 \text { patients } \\
3 \text { patients }\end{array}$ & $\begin{array}{l}7(5-9) \mathrm{cm} \\
4 \text { patients } \\
2 \text { patients } \\
2 \text { patients } \\
3 \text { patients } \\
1 \text { patients }\end{array}$ & N.S. \\
\hline $\begin{array}{l}\text { Tumour location } \\
\text { Circumferential } \\
\text { Anterior } \\
\text { Posterior } \\
\text { Lateral }\end{array}$ & $\begin{array}{l}2 \\
6 \\
6 \\
3\end{array}$ & $\begin{array}{l}1 \\
4 \\
6 \\
1\end{array}$ & N.S. \\
\hline Preoperative radiotherapy & $11 / 17$ & $5 / 12$ & N.S. \\
\hline $\begin{array}{l}\text { Dukes stage } \\
\text { A } \\
\text { B } \\
\text { C1 } \\
\text { C2 }\end{array}$ & $\begin{array}{l}5 \text { patients } \\
7 \text { patients } \\
4 \text { patients } \\
1 \text { patients }\end{array}$ & $\begin{array}{l}3 \text { patients } \\
6 \text { patients } \\
2 \text { patients } \\
1 \text { patient }\end{array}$ & N.S. \\
\hline $\begin{array}{l}\text { Distal margins } \\
1-2 \mathrm{~cm} \\
2-3 \mathrm{~cm} \\
3 \text { or more } \mathrm{cm}\end{array}$ & $\begin{array}{l}5 \text { patients } \\
10 \text { patients } \\
2 \text { patients }\end{array}$ & $\begin{array}{l}7 \text { patients } \\
5 \text { patients } \\
0\end{array}$ & N.S. \\
\hline $\begin{array}{l}\text { Circumferential margins } \\
\text { Negative } \\
\text { Positive }\end{array}$ & $\begin{array}{l}16 \text { patients } \\
1 \text { patient \# }\end{array}$ & $\begin{array}{l}12 \text { patients } \\
0\end{array}$ & N.S. \\
\hline
\end{tabular}

\# This was the patient who died in the postoperative period.

up of 6 months. Data about functional outcome at 12 months were incomplete and was not analysed.

No patient developed local recurrence within the short period of follow-up.

There was a statistically significant better function in the pouch anal anastomosis group compared with the straight anastomosis at 3 months. This was shown by less frequent bowel movements (median $3(2-5)$ versus 6 (4-8)), urgency (33\% versus $75 \%$ ), less use of constipating medications ( $42 \%$ versus $75 \%$ ) and less use of protective pads $(8.3 \%$ versus
$31 \%)$. These differences were still present at 6 months, but to a much lesser degree and did not reach statistical significance. One patient experienced difficulty in evacuation. He had a straight anastomosis using Premium CEEA 25 and had a mild anastomotic stricture, which required several dilatations under anaesthesia. None of the pouch patients experienced difficulty in evacuation. Two patients with straight anastomoses had day and night soiling at 3 months, further 2 had nocturnal soiling only and 5 in total needed to wear a protective pad at 3 months. This improved at 6 months 
Table 3: Functional results

\begin{tabular}{|c|c|c|c|c|}
\hline & \multicolumn{2}{|c|}{$\begin{array}{l}\text { Group I } \\
(n=17) \\
\text { Straight }\end{array}$} & \multicolumn{2}{|c|}{$\begin{array}{c}\text { Group II } \\
(n=12) \\
\text { J pouch }\end{array}$} \\
\hline & 3 Months & 6 months & 3 Months & 6 months \\
\hline Bowel frequency & $6(4-8) *$ & $3(2-6)$ & $3(2-5)^{*}$ & $2(2-4)$ \\
\hline Urgency & $12(75 \%)^{*}$ & $3(19 \%)$ & $4(33 \%)^{*}$ & $2(17 \%)$ \\
\hline $\begin{array}{l}\text { Continence } \\
\text { Perfect } \\
\text { Daytime leakage } \\
\text { Nocturnal leakage }\end{array}$ & $\begin{array}{l}12(75 \%) \\
2 \\
2\end{array}$ & $\begin{array}{l}14(87.5 \%) \\
1 \\
1\end{array}$ & $\begin{array}{l}11(92 \%) \\
0 \\
1\end{array}$ & $\begin{array}{l}12(100 \%) \\
0 \\
0\end{array}$ \\
\hline Use of pads & $5(31 \%)^{*}$ & $2(12.5 \%)$ & $1(8.3 \%)^{*}$ & $0(0 \%)$ \\
\hline $\begin{array}{l}\text { Use of constipating } \\
\text { medications }\end{array}$ & $12(75 \%)^{*}$ & $6(37.5 \%)$ & $5(42 \%)^{*}$ & $3(25 \%)$ \\
\hline Evacuation difficulties & $1(6 \%)$ & $1(6 \%)$ & 0 & 0 \\
\hline $\begin{array}{l}\text { Use of suppositories or } \\
\text { enemas }\end{array}$ & $1(6 \%)$ & $1(6 \%)$ & 0 & 0 \\
\hline Effect on social life & $5(31 \%)$ & $1(6 \%)$ & $2(17 \%)$ & 0 \\
\hline
\end{tabular}

* Statistically significant, McNemar Chi-Squared test

with only 1 patient still experiencing daytime leakage, another having nocturnal leakage and 2 needing pads. One patient only in the pouch group had nocturnal soiling at 3 months, which dissapeared by his 6 months review.

\section{Discussion:}

Treatment of rectal cancer often poses a challenge to treating surgeons. Attempting to achieve cure and leaving the patient with satisfactory postoperative bowel function require a lot of technical skill as well as sound judgement.

Over the last 2 decades rectal cancer surgery has evolved as a result of better understanding of the way rectal cancer spreads. Realisation that distal intramural spread is usually less than $1 \mathrm{~cm}$, except in poorly differentiated and mucinous tumours (Williams et al, 1983, Pollet \& Nicholls, 1983) has led to increasing adoption of sphincter saving resections namely ultralow anterior resections and coloanal anastomosis. The availability of stapler guns was also crucial in this regard (Williams, 1993).

Achieving adequate local clearance is paramount in reducing pelvic recurrence rates and improving survival. Understanding the significance of clear circumferential (lateral) margins and its relation to local recurrence (Quirke et al, 1986) and also the importance of mesorectal spread (Healed et al, 1982, 1986) were vital to rational rectal cancer surgery. These have led to universal acceptance of total mesorectal excision, with wide circumferential clearance in treatment of all mid and low rectal cancer.

Total mesorectal excision, by virtue of devascularizing any anorectal remnant from blood supply coming via the mesorectum has guaranteed an ever-increasing number of ultra low resections, with the potential for poor postoperative bowel function. Hallbook \& Sjodahl (2000) have estimated that approximately $50 \%$ of patients have unsatisfactory functional outcome after low restorative rectal resections, especially in the early postoperative period. These poor functional results may be temporary, lasting 6-24 months, but can also be permanent.

In 1986 French surgeons (Lazorthes et al,1986, Parc et al, 1986) proposed the addition of a replacement $\mathbf{J}$ shaped neo-rectal reservoir to increase the capacity of the neo-rectum and thus improve the functional result. This has been conclusively shown to be the case in several studies (Lazorthes et al, 1986, 1997, 
Parc et al, 1986, Seow-Cohen \& Goh, 1995, Hallbook et al, 1996, Hida et al, 1996, Ho et al, 1996, Kusunoki et al, 1997, Dehni et al, 1998, Joo et al, 1998). Most studies showed a statistically significant better function judged by less frequent bowel movements, urgency and better continence.

Colonic pouches seem to be beneficial and appropriate even in elderly population. Denhi and colleagues (1998) compared colonic pouch anal anastomosis results in 20 patients aged 75 years or more to 37 younger patients and found that both groups had similar long term functional result. They concluded that elderly patients benefit equally from ultralow restorative resections.

The functional advantage of a pouch (over a straight anastomosis) seems to decrease with time. The functional superiority of the colonic J-pouch was greatest at one year after surgery. By two years, adaptation of the straight coloanal anastomosis yielded similar functional results (Chew \& Tindal, 1997, Joo et al, 1998). Barrier and associates (1999) looked at the long term functional results of pouch-anal and straight coloanal anastomoses at mean of 10 (range 418) years in 37 patients. They found that the functional benefit of pouches seen during the first postoperative year is less evident with time and that both anastomoses types resulted in similar function long term.

Unfortunately early studies of colonic pouches have also shown that colonic pouches can result in severe evacuation difficulties in some patients (Parc et al, 1986, Marzouk 1990). Pelvic pouches are largely non-motile, depending on mass colonic movements for initiation of defaecation and helped by the increase in intraabdominal pressure created by voluntary straining. The ease of evacuation is largely governed by how vertical a pouch lies in the pelvis (how obtuse is the pouch-anal angle) to utilize these forces (Marzouk, 1990). Construction of the pouch to lie as vertical as possible in the pelvis (by a combination of constructing colonic pouches from short colonic length as well as in effect anastomosing the pouch to the top of the anal canal result in much better evacuation. Larger pouches and pouches not wedged deeply in the pelvis so as to lie vertically, tend to accumulate faecal matter and eventually angulate forward impairing evacuation (Marzouk, 1990, Williams, 1996, Marzouk 1997, Hida et al, 1999).

Use of a short 5-6 $\mathrm{cm}$ pouch has been shown in many later studies to eliminate such evacuation difficulties (Lazorthes et al, 1997, Hida et al, 1996, Joo et al, 1998) with similar postoperative bowel function in other respects.

Whether colonic pouches should only be used in coloanal anstomoses or whether its use can be extended to ultralow resections is somewhat controversial. Okholm and Christiansen (1998), contended that if a part of the rectum is preserved then the benefit of a pouch is doubtful, suggesting there is no need for use of pouches if the anastomosis was higher than $5 \mathrm{~cm}$ from anal verge. Ikeuchi and associates (1997) suggested that at least $3 \mathrm{~cm}$ of residual rectum is required if a straight anastomosis is to be used, otherwise a colonic pouch should be constructed. Hida and associates (1998) studied 48 pouches and 80 straight colorectal anastomosis in an attempt to determine the level at which a pouch provides an advantage over a straight anastomosis. They found that pouches were essential for satisfactory function when the anastomosis was $4 \mathrm{~cm}$ or less from the anal verge. They also suggested that pouches provide a benefit between 4 and $8 \mathrm{~cm}$ but not above $8 \mathrm{~cm}$ from the anal verge.

Seow-Choen (1996) suggested that all mid and low rectal cancer should be treated with a colonic pouch-anal anastomosis, citing the need for total mesorectal and total rectal excision. He also suggested that the sigmoid colon should not be used to construct a colonic pouch because it tends to lead to worse functional result.

Marzouk (1997) argued that such routine use of colonic pouches might be an overkill from the functional point of view. Past experience with ultralow rectal anastomosis with and without colonic pouches including our own since 1986 has shown that at least half the patients with straight coloanal anastomosis have satisfactory postoperative bowel function. This has led us to believe that the initial diameter of the proximal colon brought down as a neorectum determines its ability to develop an adequate reservoir soon after the operation. That is also probably the 
reason why the sigmoid colon is a poor choice in some patients when it is narrow and afflicted with diverticular disease as is usually the case in many such patients.

The aim of the present study was thus to see if a selective approach in the use of colonic pouches would improve the functional result overall in both patients needing a pouch as well as those with a straight anastomosis. We did not randomize our patients, instead the method of reconstruction was selected based upon the diameter of the proximal colon. Twenty-eight patients available for follow-up had mostly acceptable postoperative function achieved at 6 months in both groups. Poor function was only encountered in 2 patients who had a straight coloanal anastomosis. Those 2 patients had a proximal colon that admitted only the anvil of the 25 and 28 Premium CEEA stapler gun, but the shortness of the mesentry forced the use of a straight anastomosis.

While the present study still showed the functional superiority of the colonic pouches in the first 6 months postoperatively, the fact that those patients with a straight anastomosis who had a capacious proximal colon achieved a good comparable function sooner than noted in similar studies suggest that proper selection can lead to good function without the need for routine addition of colonic pouches. It is possible that true colo-anal anstomoses at the level of the dentate line would still need colonic pouches in most patients.

Most surgeons seem to favour using a diverting stoma with ultralow anterior resections and coloanal anastomosis to guard against the disastrous effects of leakage. Leakage may occur because of tenuous blood supply resulting in necrosis of the proximal colon or may occur because of a technically imperfect anastomosis. Another concern is that any pelvic sepsis from leakage may lead to fibrosis and a poorly compliant pouch and poor function long term (Wheeler and Mortensen, 1999). Other studies testify to the safety of performing these resections without a covering stoma (Mealy et al, 1992, Wang et al, 1997). A selective approach employing covering stoma whenever there is evidence of need is probably best as was done during the present study. We used stomas when leak was demonstrated on testing with air insufflation or in the presence of incomplete doughnuts. This reliability of this approach in avoiding clinical leaks has been previously confirmed (Davies et al, 1988, Beard et al, 1990). We had no clinical leaks or instances of pelvic sepsis affirming the suitability of our selective use of stomas

Colonic pouches are useful addition to colorectal practice, but it is possible to restrict their construction to those patients with narrow proximal colon and in those in which resection mandates a coloanal anastomosis.

\section{References:}

1- Barrier A, Martel P, Gallot D, Dugue L, Sezeur A, Malafosse M: Long-term functional results of colonic $\mathrm{J}$ pouch versus straight coloanal anastomosis. Br J Surg 1999; 86(9):1176-9

2- Beard JD, Nicholson ML, Sayers RD, Lloyd D, Everson NW: Intraoperative air testing of colorectal anastomoses: a prospective, randomized trial. Br J Surg 1990; 77(10):1095-7

3- Chew SB, Tindal DS: Colonic J-pouch as a neorectum: functional assessment. Aust N Z J Surg 1997; 67(9):607-10

4- Davies AH, Bartolo DC, Richards AE, Johnson CD, McC Mortensen NJ: Intraoperative air testing: an audit on rectal anastomosis. Ann R Coll Surg Engl 1988; 70(6):345-7

5- Dehni N, Schlegel D, Tiret E, Singland JD, Guiguet M, Parc R: Effects of aging on the functional outcome of coloanal anastomosis with colonic J-pouch. Am J Surg 1998;175(3):209-12

6- Dehni N, Tiret E, Singland JD, Cunningham C, Schlegel RD, Guiguet M, Parc R: Longterm functional outcome after low anterior resection: comparison of low colorectal anastomosis and colonic J-pouch-anal anastomosis. Dis Colon Rectum 1998; 41(7):817-23

7- Hallbook O, Pahlman L, Krog M, Wexner SD, Sjodahl R: Randomized comparison of straight and colonic $\mathrm{J}$ pouch anastomosis after low anterior resection. Ann Surg 1996; 224(1):58-65

8- Hallbook O, Sjodahl R: Surgical approaches to obtaining optimal bowel function. Semin Surg Oncol 2000; 18(3):249-58 
9- Heald RJ, Husband EM and Ryall RDH: The mesorectum in rectal cancer surgerythe clue to pelvic recurrence? Br J Surg 1982; 69:613-616.

10-Heald, RJ \& Ryall, RDH: Recurrence and survival after mesorectal excision for rectal cancer. Lancet 1986; i, 1479-82.

11- Hida J, Yasutomi M, Fujimoto K, Okuno K, Ieda S, Machidera N, Kubo R, Shindo K, Koh K: Functional outcome after low anterior resection with low anastomosis for rectal cancer using the colonic J-pouch. Prospective randomized study for determination of optimum pouch size. Dis Colon Rectum 1996; 39(9):986-91

12-Hida J, Yasutomi M, Maruyama T, Fujimoto K, Nakajima A, Uchida T, Wakano T, Tokoro T, Kubo R, Shindo K: Indications for colonic J-pouch reconstruction after anterior resection for rectal cancer: determining the optimum level of anastomosis. Dis Colon Rectum 1998; 41(5):558-63

13- Hida J, Yasutomi M, Maruyama T, Tokoro $\mathrm{T}$, Uchida $\mathrm{T}$, Wakano $\mathrm{T}$, Kubo R: Horizontal inclination of the longitudinal axis of the colonic J-pouch: defining causes of evacuation difficulty. Dis Colon Rectum 1999; 42(12):1560-8

14-Ho YH, Tan M, Seow-Choen F: Prospective randomized controlled study of clinical function and anorectal physiology after low anterior resection: comparison of straight and colonic $\mathrm{J}$ pouch anastomoses. Br J Surg 1996; 83(7):978-80

15-Ikeuchi H, Kusunoki M, Shoji Y, Yamamura T, Utsunomiya J: Functional results after "high" coloanal anastomosis and "low" coloanal anastomosis with a colonic J-pouch for rectal carcinoma. Surg Today 1997; 27(8):702-5

16- Joo JS, Latulippe JF, Alabaz O, Weiss EG, Nogueras JJ, Wexner SD: Long-term functional evaluation of straight coloanal anastomosis and colonic $\mathrm{J}$-pouch: is the functional superiority of colonic J-pouch sustained? Dis Colon Rectum 1998; 41(6):740-6

17-Kusunoki M, Yanagi H, Shoji Y, Yamamura T, Utsunomiya J: Anoabdominal rectal resection and colonic J pouch-anal anastomosis: 10 years' experience. Br J Surg 1997; 84(9):127780

18- Lazorthes F, Chiotasso P, Gamagami RA, Istvan $\mathrm{G}$ and Chevreau P: Late clinical outcome in a randomized prospective comparison of colonic $\mathrm{J}$ pouch and straight coloanal anastomosis. Br J Surg 1997; 84(10):1449-51. Straight vs pouch

19- Lazorthes F, Fages P, Chiotasso P, Lemozy $\mathrm{J}$, Bloom E: Resection of the rectum with construction of a colonic reservoir and colo-anal anastomosis for carcinoma of the rectum. Br J Surg 1986; 73(2):136-8

20-Lazorthes F, Gamagami R, Chiotasso P, Istvan $\mathrm{G}$ and Muhammad $\mathrm{S}$ : Prospective, randomized study comparing clinical results between small and large colonic J-pouch following coloanal anastomosis. Dis Colon Rectum 1997; 40(12):1409-13.

21-Marzouk DM: Colonic pouches in the treatment of low rectal cancer. Br J Surg 1997; 84(5):731 [letter]

22-Marzouk DM. Motility studies after colorectal surgery. MD thesis. Ain Shams University \& London University 1990

23-Mealy K, Burke, Hyland J: Anterior resection without a defunctioning colostomy: questions of safety. Br J Surg 1992; 79(4):305-7.

24-Okholm M, Christiansen J: [Does colonic $\mathrm{J}$-pouch after low anterior resection of rectal cancer give a better functional result]? [Article in Danish]Ugeskr Laeger 1998; 160(22):3198-202. [English abstract]

25-Parc R, Tiret E, Frileux P, Moszkowski E, Loygue J: Resection and colo-anal anastomosis with colonic reservoir for rectal carcinoma. Br J Surg 1986; 73(2):139-41

26-Pollet WG and Nicholls RJ: The relationship between the extent of the distal clearance and survival and local recurrence rates after curative anterior resection for carcinoma of the rectum. Ann Surg 1983; 198:159163.

27-Quirke P, Durdey P, Dixon MF and Williams NS: Local recurrence of rectal adenocarcinoma due to inadequate surgical resection: histopathological study of lateral spread tumour spread and surgical excision The Lancet 1986; 1:996-999.

28-Seow-Choen F: Colonic pouches in the treatment of low rectal cancer. Br J Surg 
1996; 83(7):881-2 [leading article]. 29-Seow-Choen F, Goh HS: Prospective randomized trial comparing $\mathrm{J}$ colonic pouch-anal anastomosis and straight coloanal reconstruction. Br J Surg 1995; 82(5):608-10

30-Wang JY, You YT, Chen HH, Chiang JM, Yeh CY, Tang R: Stapled colonic J-pouchanal anastomosis without a diverting colostomy for rectal carcinoma. Dis Colon Rectum 1997; 40(1):30-4

31-Wheeler JM, McC Mortensen NJ: Reconstructive rectal surgery. Surg Oncol 1998; 7(1-2):13-23

32-Willams NS: Sphincter saving resection and total reconstruction for low rectal cancer. In: Williams NS, ed. Colorectal cancer Clinical surgery international 20. London: Churchill Livingstone, 1996:80. 33-Willams NS. Surgical treatment of rectal cancer. In: Keighley MRB and Williams NS, eds. Surgery of the anus, rectum and colon. London: WB Saunders, 1993:1008. 34-Williams NS, Dixon MF, Johnston D: Reappraisal of the $5 \mathrm{~cm}$ rule of distal excision for carcinoma of the rectum: a study of distal intramural spread and patients' survival. Br J Surg 1983; 70:1501 